\title{
Ligand-dependent EphA7 signaling inhibits prostate tumor growth and progression
}

\author{
Shibao $\mathrm{Li}^{1,2}$, Zhiyuan $\mathrm{Wu}^{2}$, Ping $\mathrm{Ma}^{1}$, Yinhai $\mathrm{Xu}^{1}$, Yuming $\mathrm{Chen}^{2}$, Hua Wang ${ }^{3}$, Ping $\mathrm{He}^{2}$, Zhihua Kang ${ }^{2}$, Lingyu Yin ${ }^{1}$, Yao Zhao ${ }^{1}$, \\ Xinju Zhang ${ }^{4}$, Xiao Xu ${ }^{4}$, Xiaochao Ma ${ }^{5}$ and Ming Guan ${ }^{\star 2,4}$
}

The downregulation of receptor tyrosine kinase EphA7 is frequent in epithelial cancers and linked to tumor progression. However, the detailed mechanism of EphA7-mediated prostate tumor progression remains elusive. To test the role of EphA7 receptor in prostate cancer $(\mathrm{PCa})$ progression directly, we generated EphA7 receptor variants that were either lacking the cytoplasmic domain or carrying a point mutation that inhibits its phosphorylation by site-directed mutagenesis. Overexpression of wild-type (WT) EphA7 in PCa cells resulted in decreased tumor volume and increased tumor apoptosis in primary tumors. In addition, ectopic expression of WT EphA7 both can delay PCa cell proliferation and could inhibit PCa cell migration and invasion. This protein can also induce PCa cell apoptosis that correlated with increasing the protein expression levels of Bax, elevating the caspase-3 activities, reducing the protein expression levels of Bcl-2 and facilitating the dephosphorylation of Akt, which is further increased by the stimulation of ephrinA5-Fc. However, expression of these EphA7 mutants in PCa cells has no effect in vivo and in vitro. The expression of EphA7 and ephrinA5 was significantly decreased in PCa specimens compared with BPH tissues or paired normal tissues. Moreover, the phosphorylation of EphA7 was positively related with ephrinA5 expression in human prostate tissues. In sum, receptor phosphorylation of EphA7, at least in part, suppress PCa tumor malignancy through targeting PI3K/Akt signaling pathways.

Cell Death and Disease (2017) 8, e3122; doi:10.1038/cddis.2017.507; published online 12 October 2017

Prostate cancer $(\mathrm{PCa})$ is one of the most common male malignancy, and the second leading cause of death from cancer for men. ${ }^{1}$ With the aging of the population and changes in diet worldwide, an increasing number of PCa cases have been reported in recent years. ${ }^{1,2}$ Metastasis remains the primary cause of PCa-related death. ${ }^{2,3}$ Given this fact, the traditional therapeutic modalities such as surgery, chemotherapy therapy and androgen ablation therapy are only modestly effective., ${ }^{4,5}$ Therefore, understanding the molecular mechanisms contributing to PCa progression could provide insights into effective therapeutic strategies.

Eph receptors, the largest family of receptor tyrosine kinases, and their ephrin ligands not only regulate many physiological processes in the development of organs, but also have been implicated in numerous pathologies, including tumor progression. ${ }^{6,7}$ Among these Eph receptors, EphA7 receptor has attracted growing attention in tumor research. Our previous studies have shown the high prevalence of EphA7 downregulation in $\mathrm{PCa}$ patients, which can be introduced by promoter hypermethylation. ${ }^{8}$ Similar results also have been observed in other human malignancies, including colorectal cancers, ${ }^{9}$ human germinal center B-cell lymphomas, ${ }^{10}$ T-cell lymphoblastic lymphomas $^{11}$ and oral squamous cell carcinoma. ${ }^{12}$ Recently, deep sequencing analyses revealed many somatic driver mutations of EphA7 in small cell lung cancer, melanoma, and head and neck carcinoma. ${ }^{13}$ Those cancer somatic mutations were reported to span throughout the functional domains of the EphA7 receptor, and some have been shown to disrupt ephrin ligand-dependent receptor signaling. ${ }^{13}$ Moreover, in xenograft models of lymphomas, administration of the purified EPHA $7^{\text {TR }}$ protein was shown to significantly inhibit tumor growth via blocking EphA2 phosphorylation and oncogenic signals. ${ }^{14}$ Taken together, these findings show that EphA7 receptors are tumor suppressors in the relevant tumors. However, both the biological roles and the underlying molecular mechanisms of EphA7 still need to be studied in PCa.

Here, we investigated the tyrosine site and the function of EphA7 phosphorylation using overexpression of EphA7 mutants either truncating the cytoplasmic domain or carrying a point mutation in PCa cells. We showed that liganddependent EphA7 signaling resulted in the downregulation of tumor volume and the enhancement of tumor cell apoptosis in primary tumors, and significantly inhibited the proliferation, migration and invasion of PCa cells, as well as induced PCa cell apoptosis, whereas ligand-independent EphA7 signaling did not have this effect. These data imply that the phosphorylation of EphA7 receptor, at least in part, suppresses $\mathrm{PCa}$ malignancy through targeting PI3K/Akt signaling pathways.

\section{Results}

Cell density regulates EphA7 receptor phosphorylation in LNCaP cells. Eph receptor function is dependent on the

\footnotetext{
${ }^{1}$ Department of Laboratory Medicine, The Affiliated Hospital of Xuzhou Medical University, Xuzhou, China; ${ }^{2}$ Department of Laboratory Medicine, Huashan Hospital, Shanghai Medical School, Fudan University, Shanghai, China; ${ }^{3}$ Department of Laboratory Medicine, Renji Hospital, School of Medicine, Shanghai Jiaotong University, Shanghai, China; ${ }^{4}$ Department of Central Laboratory, Huashan Hospital, Shanghai Medical School, Fudan University, Shanghai, China and ${ }^{5}$ Department of Pharmaceutical Sciences, Center for Pharmacogenetics, School of Pharmacy, University of Pittsburgh, Pittsburgh, PA, USA

${ }^{*}$ Corresponding author: M Guan, Department of Central Laboratory, Huashan Hospital, Shanghai Medical College, Fudan University, 12 Central Urumqi Road, Shanghai 200040, China. Tel: +86 021 52888048; Fax: +86 021 96567576; E-mail: guanming88@yahoo.com

Received 28.4.17; revised 08.8.17; accepted 17.8.17; Edited by A Stephanou
} 
a

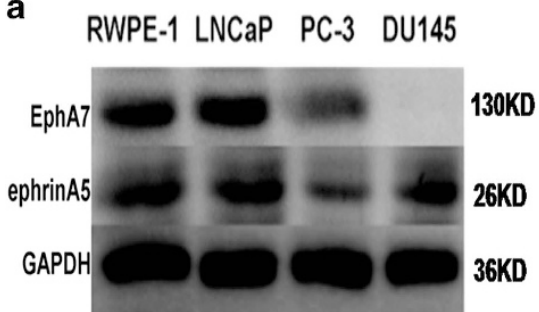

C
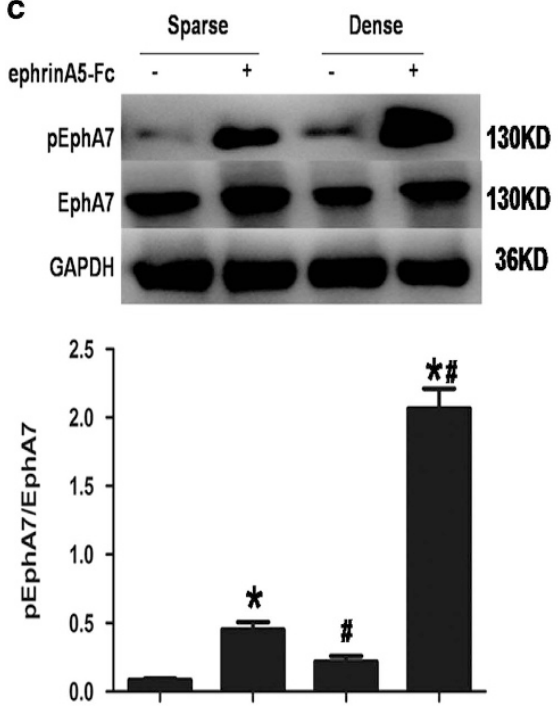

b

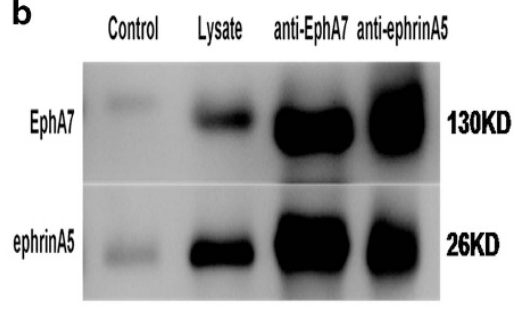

d
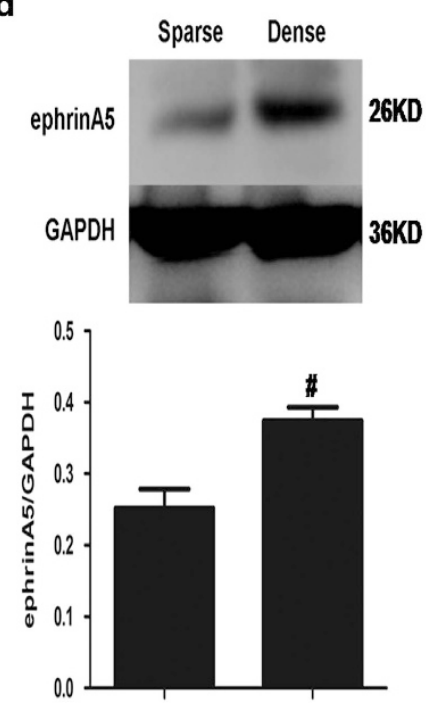

Figure 1 The phosphorylation of EphA7 receptor was regulated by cell density. (a) The protein expression of EphA7 and ephrinA5 was analyzed by western blotting in four prostate cell lines. (b) The interaction between EphA7 and ephrinA5 in $\mathrm{LNCaP}$ cells by co-immunoprecipitation and western blot analysis. (c) The phosphorylation analysis of EphA7 receptors by immunoprecipitation. Dense (approximately 100\% confluence) and sparse (approximately $30 \%$ confluence) LNCaP cells were serum-deprived for $24 \mathrm{~h}$ and then stimulated with $1.0 \mu \mathrm{g} / \mathrm{ml}$ ephrinA5-Fc or Fc for $15 \mathrm{~min}$. The EphA7 protein was enriched using immunoprecipitationwith anti-EphA7 antibody and then divided in two aliquots for immunoblotting with anti-EphA7 antibody and anti-phosphotyrosine (4G10) antibody. (d) Western blot analysis of expression of the ephrinA5 ligand. Data are shown as the mean \pm S.D. ${ }^{*} P<0.05$, versus the corresponding LNCaP cells without the stimulation of ephrinA5-Fc; ${ }^{\#} P<0.05$, versus the correspondingly sparse LNCaP cells

stimulation of its homologous ligand, ephrin. Prior studies have shown that the optimum ligand of EphA7 is ephrinA5. ${ }^{15}$ We explored whether the optimum ligand of EphA7 is also ephrinA5 in $\mathrm{PCa}$, whether the phosphorylation of EphA7 receptors is related to the stimulation of endogenous ephrinA5 ligand in a cell-cell contact-dependent manner and whether the exogenous ephrinA5 ligand can further elevate the level of EphA7 tyrosine phosphorylation. The ephrinA5-EphA7 complexes were observed by coimmunoprecipitation in LNCaP cell lysates (Figure 1b), which highly expresses both the endogenous ephrinA5 ligand and the endogenous EphA7 receptor (Figure 1a). Also, the level of phosphorylated EphA7 receptor was upregulated by cell density, and was able to be further enhanced by the stimulation of exogenous ephrinA5 ligand (Figure 1c). Furthermore, with increasing cell density, the ephrinA5 expression level gradually increased, whereas no obvious difference on EphA7 expression was observed in different cell density groups (Figures $1 \mathrm{c}$ and d). These results showed that the tyrosine phosphorylation of the EphA7 receptor was regulated by its ligand ephrinA5 and cell density.
Tyrosine 791 of EphA7 is the major phosphorylation site for the EphA7 receptor in PCa. To explore the role of EphA7 receptor phosphorylation, we first predicted several potential phosphorylated sites of tyrosine via sequence analysis (www.phosphositeplus.org) and generated the human wild-type (WT) EphA7 cDNA and the following EphA7 mutants: $Y 597 \mathrm{~F} / \mathrm{Y} 608 \mathrm{~F} / \mathrm{Y} 614 \mathrm{~F}$ in the juxtamembrane domain (DM); Y791F in the kinase domain (KD); and the $\Delta$ Cyto mutant lacking the entire cytoplasmic region (Figure 2a). The resultant mutants were tested in PCa cell lines (PC-3, and DU145), which either express very low levels of endogenous EphA7 or do not express endogenous EphA7. As shown in Figures $2 \mathrm{~b}$ and $\mathrm{c}$, the phosphorylated EphA7 receptor was detected in the WT EphA7 and DM-mutant group, whereas overexpression of the KD mutant or $\triangle$ Cyto forms of EphA7 failed to confer the phosphorylation of EphA7 receptor in EphA7-deficient cells, implying that the tyrosine 791 of the cytoplasmic domain is critical to EphA7 receptor phosphorylation. Interestingly, no endogenous EphA7 protein was observed using immunoprecipitation in PC-3 cells, which expressed extremely low levels of EphA7 protein in Figure 1a. This discrepancy may be the contribution of low sensitivity of immunoprecipitation. 


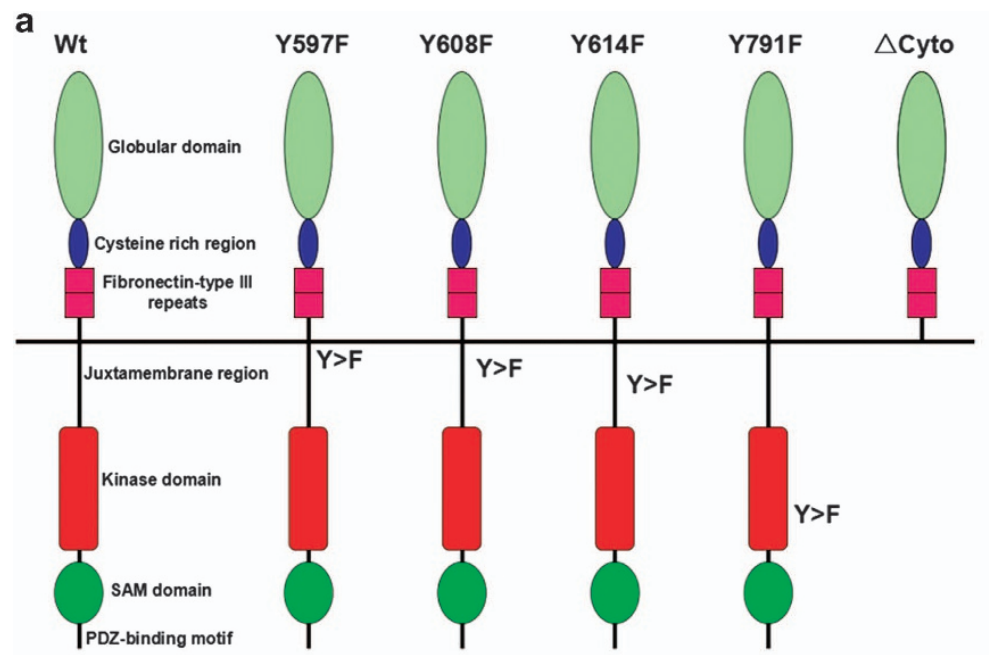

b
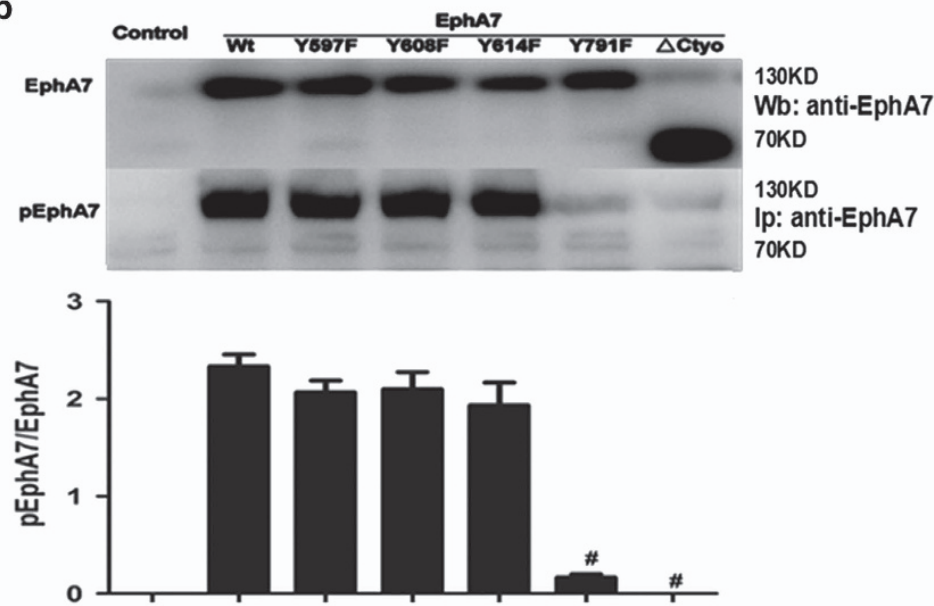

C
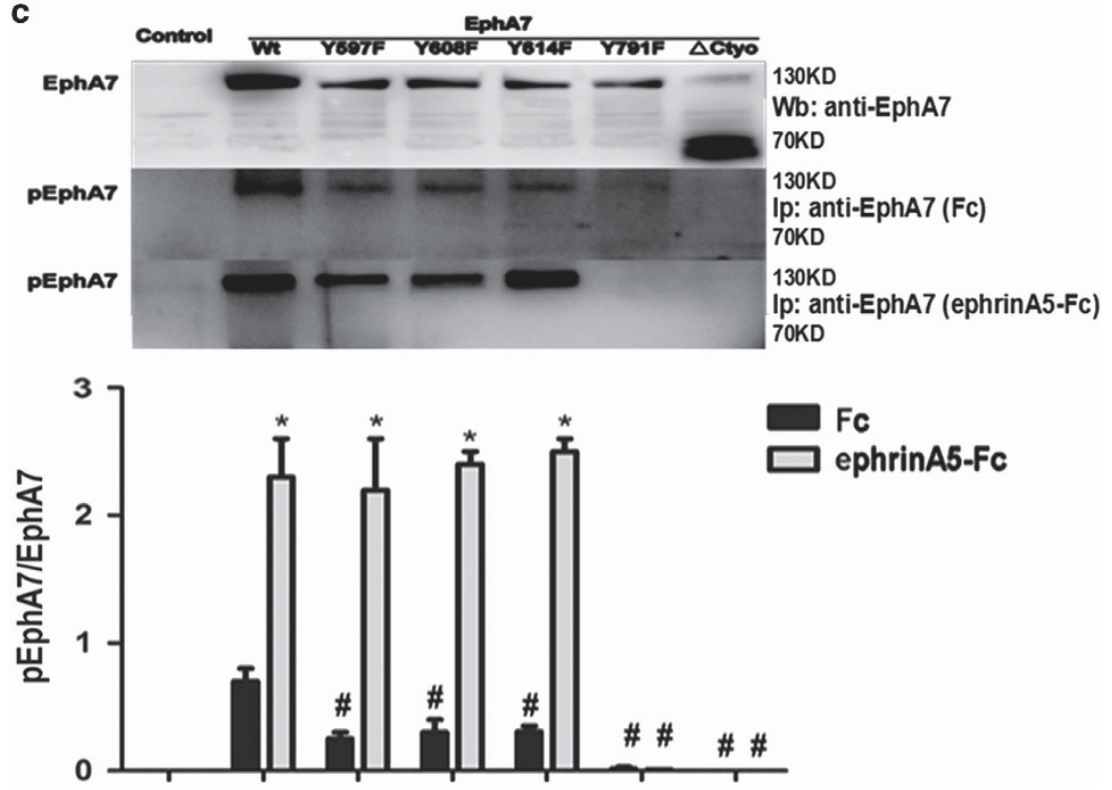
Then, we analyzed the EphA7 receptor phosphorylation in response to ephrinA5-Fc treatment in PC-3 cell lines. Data showed that the overexpression of DM or WT of the EphA7 mutant resulted in a substantial enhancement of ligandindependent EphA7 receptor phosphorylation, which was further enhanced by the ephrinA5-Fc treatment, implying that the phosphorylation of EphA7 receptor required the stimulation of ephrinA5-Fc (Figure 2c). Taken together, these data suggest that the primary phosphorylation site of EphA7 is tyrosine 791 , and dependent on the stimulation of ephrinA5 ligand.

Ligand-dependent inhibition of tumor cell growth by EphA7 in PCa requires Y791 phosphorylation. To evaluate whether the phosphorylation of the EphA7 receptor could affect tumor growth, we first analyzed the effect of different EphA7 mutants forms on tumor growth in vivo. A subcutaneous xenograft model was established using PC-3/Control, PC-3/EphA7(WT), PC-3/EphA7(KD) or PC-3/EphA7( $\triangle$ Cyto) cells in nude mice. The primary tumors of PC-3/EphA7(WT) grew slower than the PC-3/Control tumors, PC-3/EphA7(KD) tumors and $\mathrm{PC}-3 /$ EphA7( $\triangle$ Cyto) tumors. However, there was no significant difference in tumor growth rate between the PC-3/Control tumors and the PC-3/EphA7(KD) tumors, as well as the PC-3/EphA7( $\triangle$ Cyto) tumors (Figure $3 b)$. Similarly, the average tumor weights of the PC-3/EphA7(WT) primary tumors were significantly less than those of the PC-3/Control tumors, the PC-3/EphA7(KD) tumors and the PC-3/EphA7 $(\triangle$ Cyto) tumors $(P<0.05)$ (Figure $3 a)$. The above results suggest that WT EphA7 receptor inhibit prostate tumor growth in vivo.

Next, PCa cells proliferating ability was detected in DU145 cells and PC-3 cell lines. As shown in Figures $3 c$ and $d$, compared with control cells, the capacity of cell proliferation was slowing-down in overexpression of WT EphA7 cell, which was further aggravated by the ephrinA5-Fc administration in PC-3 cells that express very low levels of endogenous ephrinA5. In contrast, stably transfected PCa cells with the KD mutant or $\triangle$ Cyto forms of EphA7 did not show any significant difference in cell proliferation. Similar results have been observed by Ki-67 IHC staining of primary tumors in a subcutaneous xenograft model (Supplementary Figure S1). These intriguing results suggest that the suppressive effect of EphA7 receptor is dependent on the phosphorylation of tyrosine 791 and on the stimulation of the exogenous ephrinA5 ligand.

Ligand-dependent inhibition of cell migration and invasion by EphA7 in $\mathrm{PCa}$ requires Y791 phosphorylation. Then, we assess the effects of EphA7 phosphorylation on the ability of PCa cells to migrate and invade using the scratch migration and Matrigel invasion assays. Migratory ability was significantly decreased in DU145/EphA7(WT) cells compared with DU145/EphA7(Control) cells, DU145/EphA7(KD) cells and DU145/EphA7( $\triangle$ Cyto) cells (Figure 4a). PC-3/EphA7 (WT) cells showed a slight reduction in migration, but the stimulation of ephrinA5-Fc significantly decreased cell migration, whereas PC-3/EphA7(KD) cells and PC-3/EphA7 ( $\triangle$ Cyto) cells were unaffected (Figure $4 c$ ). Similarly, the Matrigel invasion assays displayed that the number of invasive cells was significantly reduced in the EphA7(WT) group compared with control and EphA7(KD) groups, as well as $\operatorname{EphA7}(\triangle \mathrm{Cyto})$ group, and was further decreased by the ephrinA5-Fc administration in the PC-3/EphA7(WT) group (Figures $4 b$ and $d$ ). These intriguing results suggest that the suppressive effect of EphA7 receptor on tumor migration and invasion is dependent on the phosphorylation of tyrosine 791 and the stimulation of ephrinA5 ligand.

Tyrosine 791 phosphorylation of EphA7 induces prostate carcinoma cell apoptosis. Next, we investigated whether tyrosine 791 phosphorylation of EphA7 can induce PCa cell apoptosis. Compared with the control and mutant groups, the PCa cell apoptosis rate was significantly increased in the WT EphA7 group $(P<0.01$, Figures $5 \mathrm{a}$ and b). Western blot determination also indicated that WT EphA7 upregulated cleaved caspase-3 protein, which was further increased by ephrinA5-Fc administration (Figures $5 c$ and d). Meanwhile, as expected, the number of apoptosis cells significantly increased in WT EphA7 expressing tumors compared with the control group by active-caspase-3 staining in vivo, whereas the EphA7 mutant-expressing tumors, either EphA7(KD) or EphA7( $\triangle$ Cyto), showed little or no apoptosis (Supplementary Figure S1). These data support the idea that EphA7-inducing apoptosis requires the kinase-dependent signaling of EphA7 receptor.

Involvement of the PI3K/Akt signaling pathway in tyrosine 791 phosphorylation of EphA7-induced cell apoptosis in PC-3 cells. The PI3K/Akt signal pathway participated in the regulation of cell proliferation, survival and apoptosis via various downstream effectors, such as the $\mathrm{Bcl}-2$ family. Alterations in the expression levels of PI3K/Akt signaling molecules were evaluated in PC-3 cells posttransfection with EphA7 for $48 \mathrm{~h}$. Compared with the control group, the level of pAkt and Bcl-2, an anti-apoptotic protein, was significantly reduced in PC-3/EphA7(WT) cells, whereas the elevated protein level of Bax was observed in PC-3/ EphA7(WT) cells, which was able to be further increased by treatment of ephrinA5-Fc. In addition, the expression levels of total Akt were unchanged between the control cells and PC-3/EphA7(KD) cells, as well as PC-3/EphA7( $\triangle$ Cyto) cells (Figure 6). These results suggest that EphA7-induced $\mathrm{PCa}$ cell apoptosis may be closely related to the PI3K/Akt signaling pathway.

\footnotetext{
Figure 2 Tyrosine 791 of EphA7 is the major phosphorylation site for the EphA7 receptor in PCa cells. (a) A diagram of EphA7 receptor structure and mutants. (b) The expression and phosphorylation of EphA7 in DU145 cells stably overexpressing either WT EphA7 receptor or EphA7 mutants. (c) The expression and phosphorylation of EphA7 in PC-3 cells stably overexpressing either EphA7(WT) receptor or EphA7 mutants. Cells were serum-deprived for $24 \mathrm{~h}$ and then stimulated with $1.0 \mu \mathrm{g} / \mathrm{ml}$ of ephrinA5 ligand or Fc for $15 \mathrm{~min}$. After cell lysis, EphA7 was immunoprecipitated with anti-EphA7 antibody and then divided into two aliquots for immunoblotting with anti-EphA7 antibody and antiphosphotyrosine (4G10) antibody. Data are shown as the mean \pm S.D. ${ }^{\#} P<0.05$, versus the respective WT EphA7 group, ${ }^{*} P<0.05$, versus the respective control group
} 
a
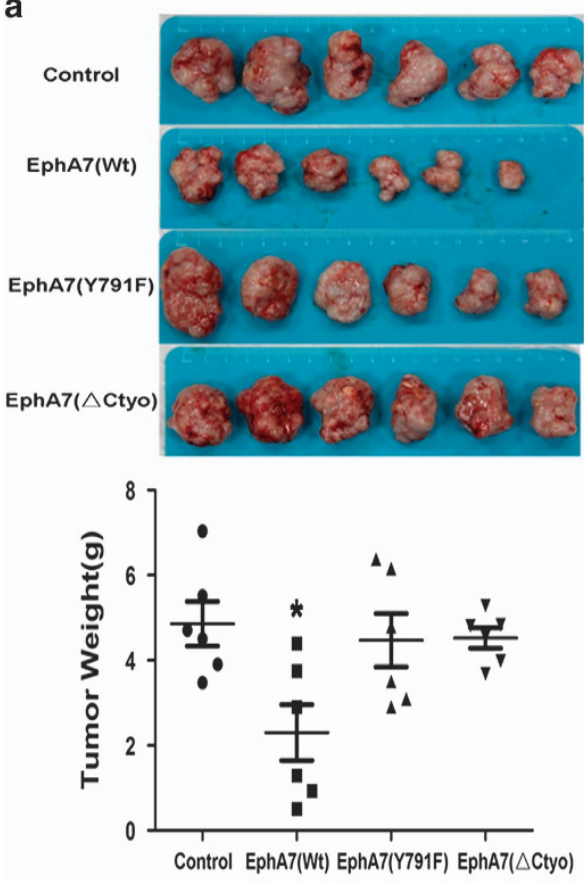

b

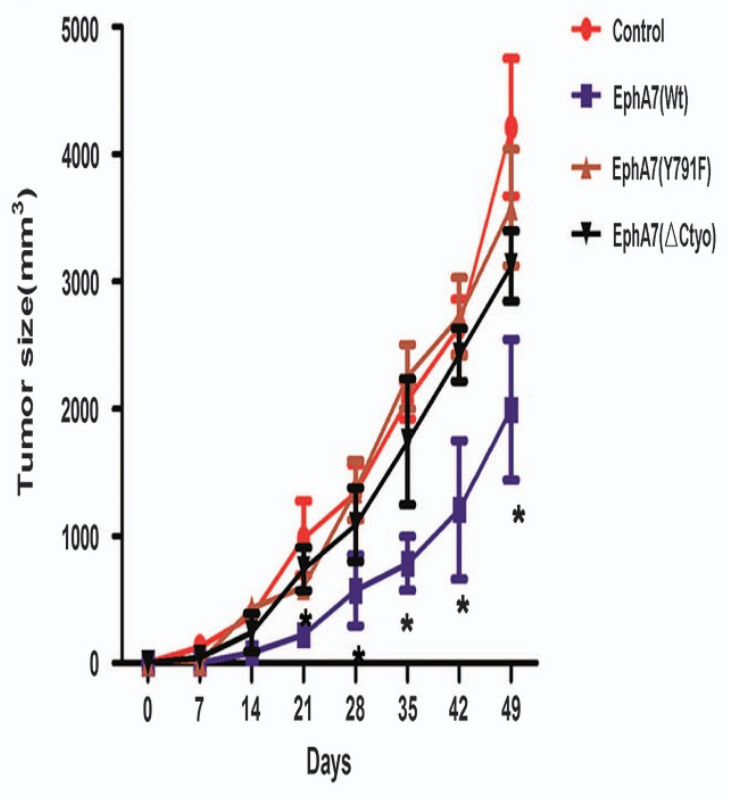

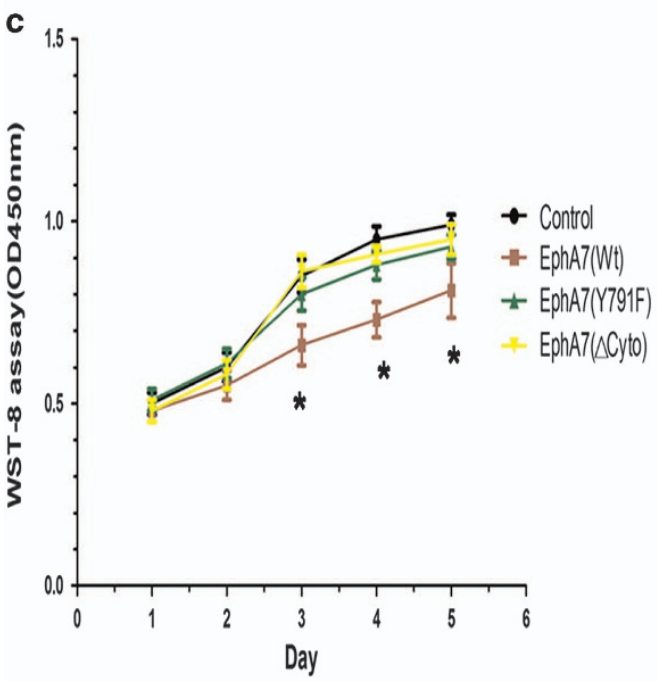

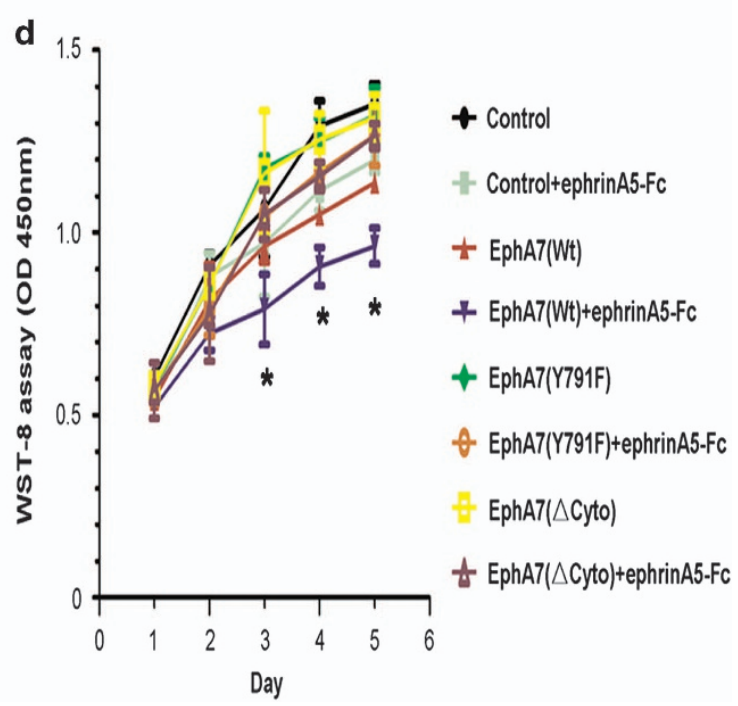

Figure 3 WT EphA7 inhibit tumor growth in vitro and in vivo. (a) Subcutaneous xenograft PCa models were generated using PC-3/Control, PC-3/EphA7(WT), PC-3/EphA7 (KD), or PC-3/EphA7( $\Delta$ Cyto) cells. After mice had been terminally narcotized and killed over 49 days, tumors were removed and the weights measured. The average horizontal lines represent the means in the groups. (b) Tumor growth was monitored over seven weeks, and the average tumor volumes of primary tumors were calculated (six mice per group). (c) The proliferation of DU145 cells stably overexpressing either EphA7(WT) receptor or EphA7 mutants was evaluated using a colorimetric WST-8 assay. (d) Proliferation of PC-3 cells overexpressing the EphA7(WT) receptor or EphA7 mutants. Cells were plated in 96-well plates and then serum-deprived for $24 \mathrm{~h}$. After stimulation of $1.0 \mu \mathrm{g} / \mathrm{ml}$ of ephrinA5 ligand or Fc, cell viability from $24 \mathrm{~h}$ (To) and seven days (T7) in culture was determined using a colorimetric WST-8 assay. Data are shown as the mean \pm .S.D. ${ }^{*} P<0.05$, versus the respective control group

The phosphorylation of EphA7 is positively related with ephrinA5 expression in human prostate tissues. To investigate whether the phosphorylation of EphA7 is correlated to ephrinA5 expression in clinical samples, we first used real-time PCR analysis to examine the mRNA level of EphA7 and its ligand ephrinA5 in 50 benign prostate hyperplasia (BPH) tissues and $64 \mathrm{PCa}$ specimens. Compared with $\mathrm{BPH}$ tissues or paired normal tissues, 45.3\% (29/64) PCa samples and $60.9 \%$ (39/64) PCa tissues, respectively, displayed the downregulation of EphA7 mRNA and the decline of ephrinA5 transcript. The association analysis between clinicopathologic parameters and EphA7 mRNA expression, as well as ephrinA5 transcript level showed that the level of ephrinA5 transcript was negatively correlated with Gleason score $(P=0.013)$ and TNM staging $(P=0.016$; Table 1$)$.

We next analyzed the protein expression of ephrinA5 and EphA7, as well as the phosphorylation of EphA7 in 20 pairs $\mathrm{PCa}$ and normal tissues by immunohistochemistry (IHC) 
a
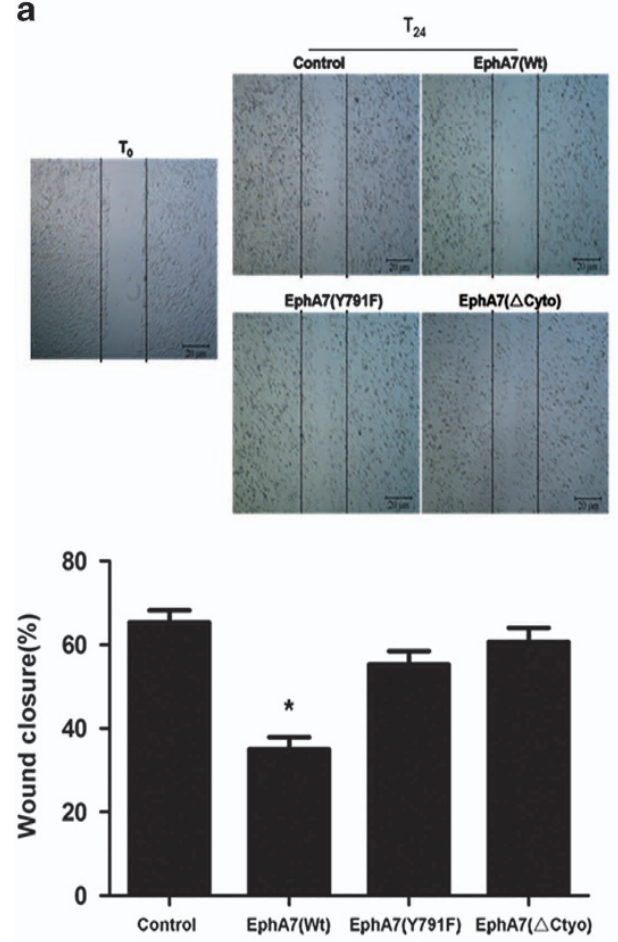

c
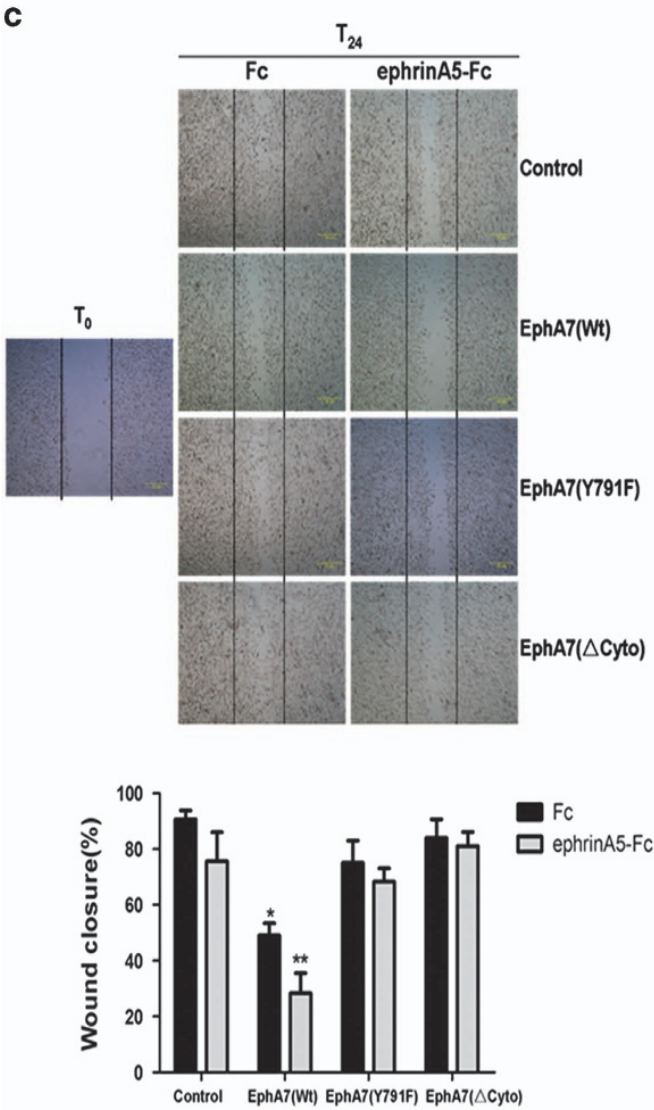

b

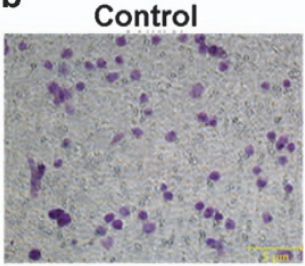

EphA7(Y791F)

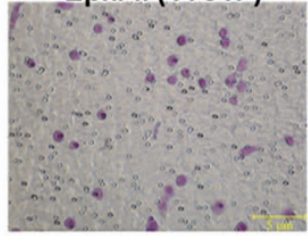

EphA7( $\triangle$ Cyto)

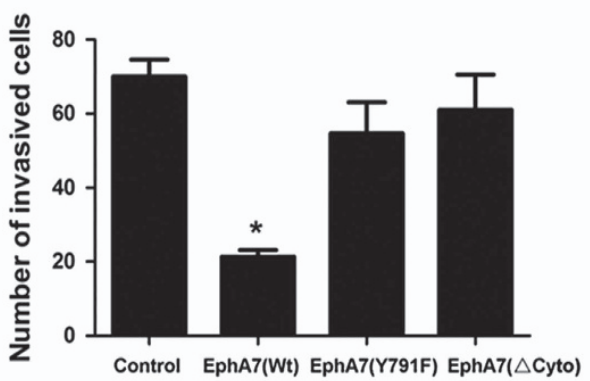

d
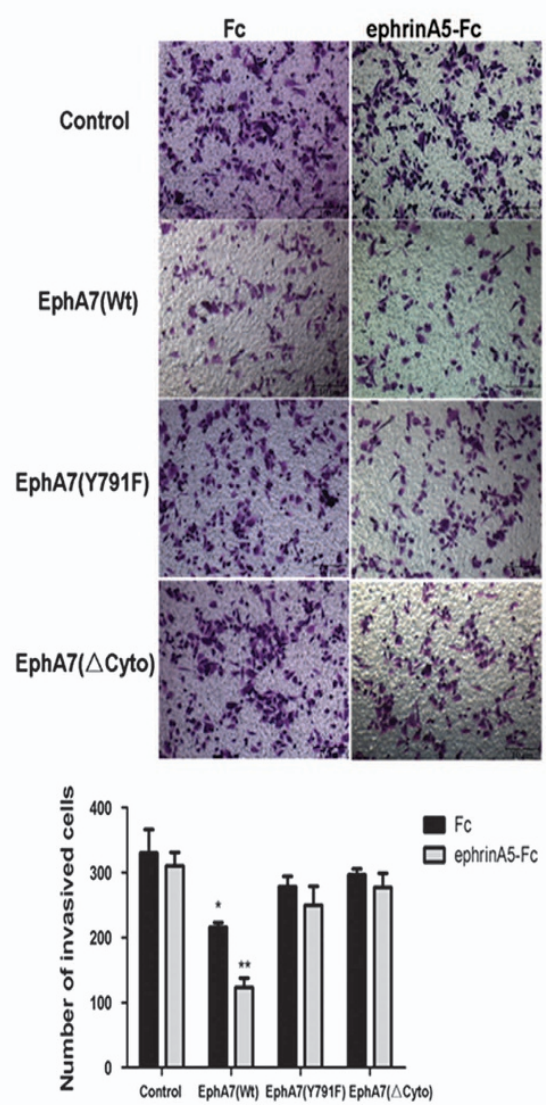
Figure 4 Ligand-dependent inhibition of cell migration and invasion by EphA7 in PCa. (a) DU145 cell migration activity was measured using the wound healing assay. (b) DU145 cell invasion activity was detected with the Matrigel invasion assay ( $\times 100)$. (c) PC-3 cell migration activity was measured using the wound healing assay. Cells were serum-deprived for $24 \mathrm{~h}$, scratched with a tip and photographed (T0). After stimulation of $1.0 \mu \mathrm{g} / \mathrm{ml}$ of ephrinA5 ligand or Fc for 15 min, cells were cultured in complete medium for $24 \mathrm{~h}$ and photographed (T24). (d) PC-3 cell invasion activity was detected with the Matrigel invasion assay ( $\times 100)$. A total of $5 \times 10^{4}$ cells were plated in transwell inserts, treated with $1.0 \mu \mathrm{g} / \mathrm{ml}$ of ephrinA5 ligand or Fc for $15 \mathrm{~min}$ and cultured for $24 \mathrm{~h}$. All experiments were performed in triplicate. Data are shown as the mean \pm S.D. ${ }^{*} P<0.05$ versus the respective control group, ${ }^{* *} P<0.05$ versus the respective EphA7(WT) expression group

a

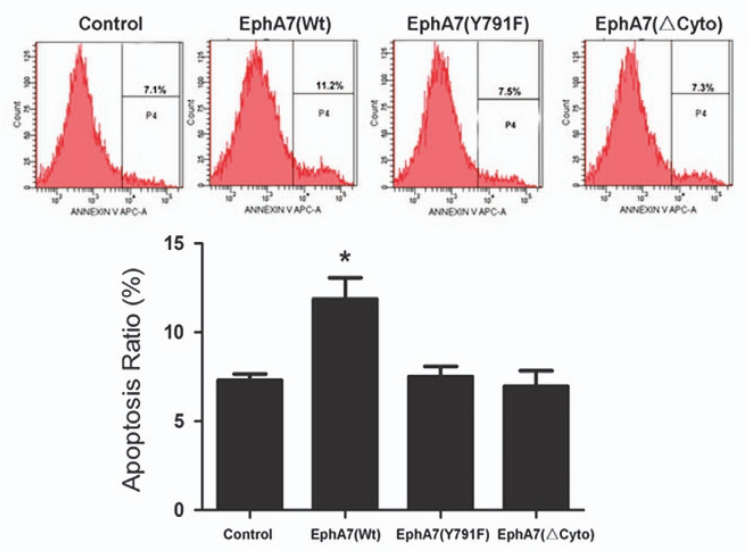

C
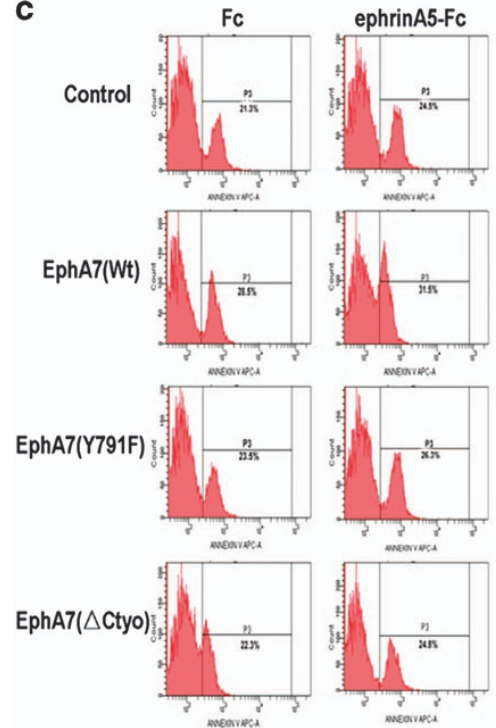

b
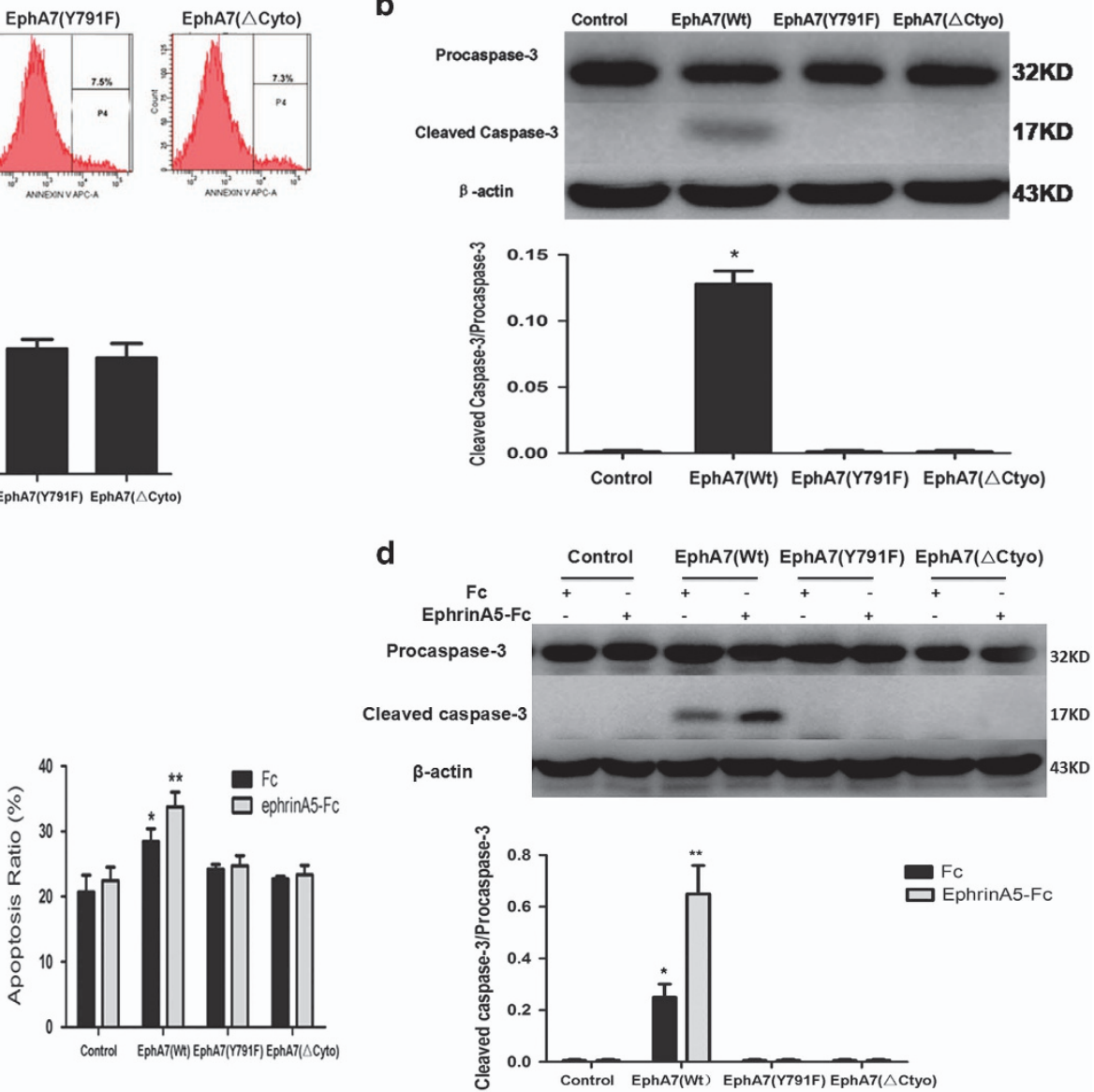

Figure 5 Ligand-dependent promotion of cell apoptosis by EphA7 in PCa. (a) DU145 cell apoptosis was analyzed by FACS after Annexin V-APC staining. (b) Western blot analysis of procaspase-3 and cleaved caspase-3 expression in DU145 cell-overexpressing EphA7(WT) receptor or EphA7 mutants. (c) PC-3 cell apoptosis was analyzed by FACS after Annexin V-APC staining. A total of $5 \times 10^{6} \mathrm{PC}-3$ cells overexpressing EphA7(WT) receptor or EphA7 mutants were serum-deprived for $24 \mathrm{~h}$, and treated with $1.0 \mu \mathrm{g} / \mathrm{ml}$ of ephrinA5 ligand or Fc for $15 \mathrm{~min}$. Then, cells were stained using Annexin V-APC and quantified by FACS. (d) Western blot analysis of procaspase-3 and cleaved caspase-3 expression in PC-3 cells overexpressing EphA7(WT) receptor or EphA7 mutants. PC-3 cells overexpressing EphA7(WT) receptor or EphA7 mutants were serum-deprived for $24 \mathrm{~h}$, treated with $1.0 \mu \mathrm{g} / \mathrm{ml}$ of ephrinA5 ligand or Fc for $15 \mathrm{~min}$ and lysed. Then, cell lysate was immunoprecipitated with anti-procaspase-3 antibody and anti-cleaved caspase-3 antibody. Data are shown as the mean \pm S.D. ${ }^{*} P<0.05$ versus the control group. ${ }^{* \star} P<0.05$ versus the respective EphA7(WT) expression group

staining or western blotting. Representative IHC results displayed that immunostaining of the EphA7 and ephrinA5 protein could be observed in the cytoplasm of all paired noncancerous tissues. Among the 20 prostate carcinoma specimens, $13(65.0 \%)$ exhibited undetectable or weak ephrinA5 immunostaining, and $40.0 \%$ (8/20) of the tumor tissues had no intense immunostaining of the EphA7 protein (Figure 7a). Western blotting analysis displayed that the level of both EphA7 phosphorylation and ephrinA5 expression was significantly decreased in PCa tissues compared with that in normal tissues (Figure $7 \mathrm{~b}$ ), and that the expression of ephrinA5 positively correlated with the ratio of $\mathrm{pEphA7/EphA7}$ in $\mathrm{PCa}$ tissues (Figure 7c), implying that the phosphorylation of EphA7 may be regulated by ephrinA5 in PCa progression.

\section{Discussion}

Our previous studies showed that EphA7 is epigenetically reduced or lost in $\mathrm{PCa}$ and that the ectopic expression of 

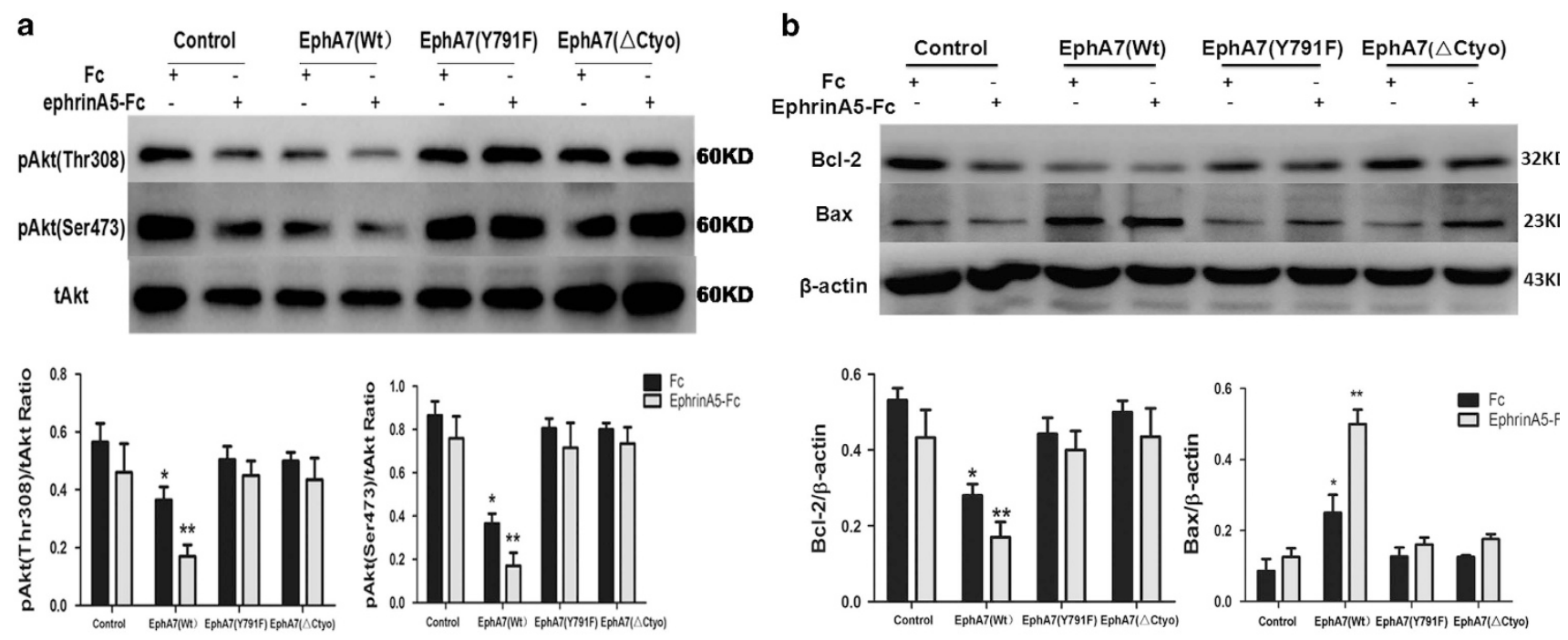

Figure 6 Ligand-dependent EphA7 signal influences the expression levels of pAkt(Thr308), pAkt(Ser473), Bcl-2 and Bax in PC-3 cells. PC-3 cells, overexpressing EphA7 (WT) receptor or EphA7 mutants, were cultured under the fetal bovine serum-free RPMl-1640 media for $24 \mathrm{~h}$, treated with $1.0 \mu \mathrm{g} / \mathrm{ml}$ of ephrinA5 ligand or Fc for $15 \mathrm{~min}$, and lysed. Cell lysate was immunoprecipitated with anti-pAkt(Thr308) antibody, anti-pAkt(Ser473) antibody and anti-tAkt antibody (a), as well as anti-Bcl-2 antibody, anti-Bax antibody and anti- $\beta$-actin antibody (b). All experiments were performed in triplicate. Data are shown as the mean \pm S.D. ${ }^{*} P<0.05$ versus the control group. ${ }^{\star \star} P<0.05$ versus the respective EphA7(WT) expression group

Table 1 Correlation of expression of EphA7 mRNA and ephrinA5 transcript with clinical and histological parameters in PCa patients

\begin{tabular}{|c|c|c|c|c|c|c|}
\hline & \multicolumn{2}{|c|}{ EphA7 mRNA expression } & \multirow[b]{2}{*}{$P$-value ${ }^{a}$} & \multicolumn{2}{|c|}{ ephrinA5 mRNA expression } & \multirow[b]{2}{*}{$P$-value } \\
\hline & Normal & Reduced & & Normal & Reduced & \\
\hline \multicolumn{7}{|c|}{ Age (years) } \\
\hline$\leq 70$ & 20 & 14 & 0.479 & 14 & 20 & 0.712 \\
\hline$>70$ & 15 & 15 & & 11 & 19 & \\
\hline \multicolumn{7}{|c|}{$P S A(n g / m l)$} \\
\hline$\leq 10$ & 7 & 7 & 0.690 & 4 & 10 & 0.363 \\
\hline$>10$ & 28 & 22 & & 21 & 29 & \\
\hline \multicolumn{7}{|c|}{ Stage (TNM) } \\
\hline $\mathrm{T} 1-\mathrm{T} 2$ & 14 & 15 & 0.348 & 16 & 13 & 0.016 \\
\hline T3-T4 & 21 & 14 & & 9 & 26 & \\
\hline \multicolumn{7}{|c|}{ Gleason score } \\
\hline $6-7$ & 7 & 6 & 0.946 & 9 & 4 & 0.013 \\
\hline $8-10$ & 28 & 23 & & 16 & 35 & \\
\hline \multicolumn{7}{|c|}{ Prostate volume $(\mathrm{ml})$} \\
\hline$\leq 50$ & 25 & 20 & 0.830 & 18 & 27 & 0.813 \\
\hline$>50$ & 10 & 9 & & 7 & 12 & \\
\hline
\end{tabular}

Normal: $0.5 \leq 2^{-\Delta \Delta C t} \leq 2 ;$ Reduced: $2^{-\Delta \Delta C t}<0.5$.

$x^{2}$ (two-tailed).

EphA7 is involved in prostate carcinogenesis. ${ }^{8}$ However, the underlying molecular mechanisms involved are still ill defined. In the present study, we provide substantial evidence that EphA7, as a tumor suppressor, restrains PCa cell migration and invasion via delaying cell growth and inducing cell apoptosis in response to its cognate ligand ephrinA5. Whereas, the EphA7 deletion mutant, carrying a Y791F point mutation (KD) or lacking its cytoplasmic region ( $\triangle$ Cyto), does not have this effect in vivo and in vitro. This observation suggests that EphA7 receptor phosphorylation may be required for EphA7 signaling-mediated tumor progression. In our model, after ephrinA5 specifically bound to EphA7, the level of EphA7 receptor phosphorylation significantly increased and the EphA7 phosphorylation was negatively correlated with prostate carcinogenesis. Furthermore, EphA7 signaling not only greatly enhanced the apoptosis-inducing signaling molecules activity of Bax and active-caspase-3 but also inhibited the expression of anticancer molecules Bcl-2 and the phosphorylation levels of Akt, a pivotal regulated kinase of the PI3K/Akt signaling pathway. These results support the action of EphA7 as a negative regulator of $\mathrm{PCa}$ progression via a ligand-dependent mechanism.

As a member of the Eph receptors group, EphA7 is highly conserved in vertebrates from fish to humans, ${ }^{16}$ and has a sometimes paradoxical role in cancer. ${ }^{17-19}$ Previous studies have demonstrated that EphA7 is epigenetically silenced in the progression of many tumors, implying that EphA7 may act as a tumor suppressor. ${ }^{9,12}$ Meanwhile, various other studies have confirmed that EphA7 not only is overexpressed in the stomach, ${ }^{18}$ pancreas ${ }^{20}$ and lung, ${ }^{21}$ but also promotes tumor 
a
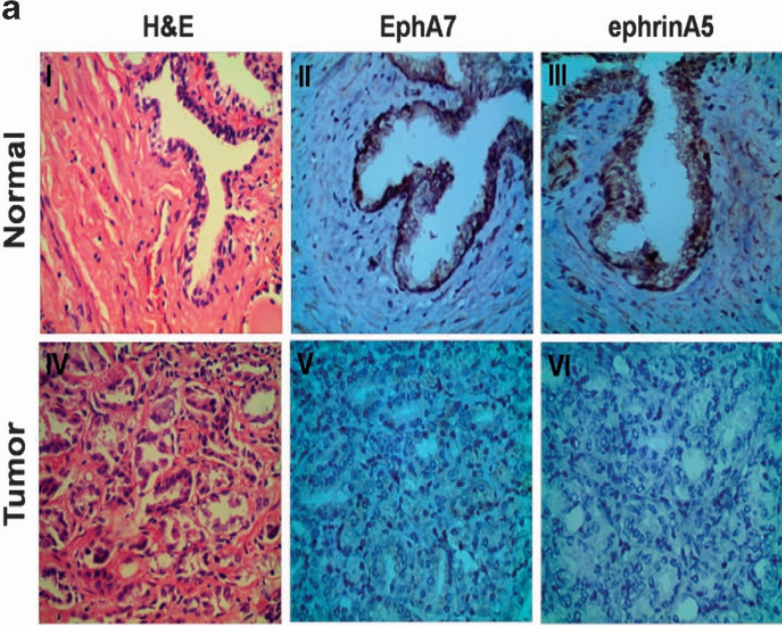

b
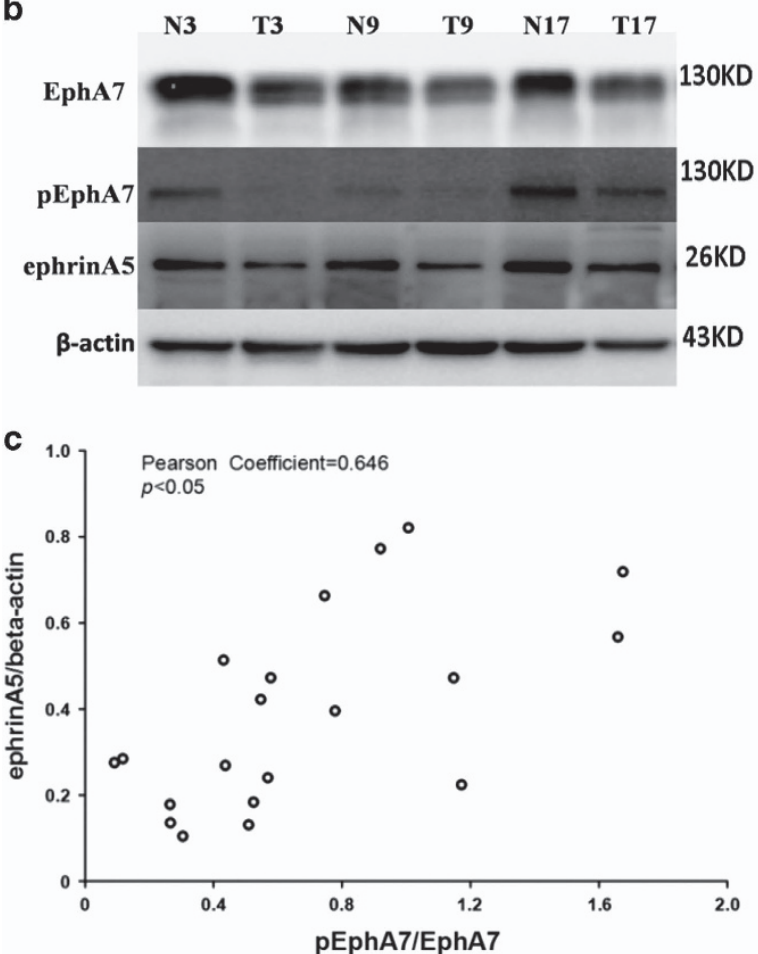

Figure 7 The phosphorylation of EphA7 receptor and the expression of EphA7 and ephrinA5 in human prostate tissues. (a) Representative photographs of EphA7 and ephrinA5 immunostaining in prostate tissue. (I-III) The adjacent non-cancerous prostate tissue. (IV-VI) The prostate carcinoma tissue (magnification, $\times 400$ ). (b) Representative phosphorylation analysis of EphA7 receptors and the expression of EphA7 and ephrinA5 in human prostate tissues. (c) pEphA7/EphA7 correlates with ephrinA5 expression. Data are shown as the mean \pm S.D.

development by inhibiting carcinoma cell apoptosis, increasing cancer cell proliferation, and facilitating invasion and migration, suggesting that EphA7 receptors can contribute to tumor progression. ${ }^{22,23}$ The contradictory findings above prompted us to ask whether the EphA7 receptor is prooncogenic or anti-oncogenic in PCa. In our study, we examined the biological role of EphA7 in PCa cell lines and found that EphA7 significantly inhibited cell migratory and invasive capabilities in vitro. A previous microarray analysis of the gene expression profiling of LNCaP cells (androgen dependent) and LNCaP derived C4-2 cells (androgen independent) suggested that EphA7 is one of the upregulated genes in LNCaP but is not expressed in C4-2. ${ }^{24}$ Lee et al. ${ }^{25,26}$ carried out a series of studies on EphA7 receptor function during early brain development and have shown that the EphA7 receptor interacts with death receptors such as tumor necrosis factor receptor 1 (TNFR1) to induce neural epithelial cell apoptosis and to decrease cell viability. In addition, they demonstrated that EphA7 negatively regulates neural progenitor cell proliferation in brain development. ${ }^{25,26}$ Consistent with the previous studies, ${ }^{12,25,26}$ our study showed that the overexpression of EphA7 also significantly inhibited cell proliferation and induced $\mathrm{PCa}$ cell apoptosis in vitro and in vivo, which delayed the primary tumor growth in vivo. However, the ectopic expression of the EphA7 deletion mutant, carrying a Y791F point mutation (KD) or lacking its cytoplasmic region ( $\triangle \mathrm{Cyto}$ ), did not have this effect in vivo and in vitro, suggesting that the anti-oncogenic functions of EphA7 may be involved in the tyrosine phosphorylation of EphA7 kinase domain.

Classic oncogenic transformation by the Eph receptor includes elevated levels of receptor phosphorylation. However, it is not clear whether receptor phosphorylation is required for EphA7 receptor-mediated oncogenic transformation. Ligand binding triggers Eph receptor phosphorylation. Given the diverse nature of Eph-ephrin interactions, EphA7 can bind all five ephrinA ligands. However, the ephrin expression profile has its specificity in different tissues, which results in the selectivity and specificity of ephrinA ligand combined with EphA7. Noberini et al. ${ }^{15}$ carried out a study on measuring the binding of ephrin-Fc fusion proteins to Eph receptors and found that the natural ligand of EphA7 was ephrinA5 by ELISA and pull-down assays. Consistent with these data, the current study identified the interaction between EphA7 and ephrinA5 in PCa cells and revealed EphA7 tyrosine phosphorylation of $\mathrm{PCa}$ cells, which can be further elevated by the stimulation of ephrinA5-Fc, implying that the biological function of EphA7 is regulated by its homologous ligand ephrin $\mathrm{A} 5$ in PCa. Additional analysis of the downstream signaling pathways of EphA7 receptors dependent on ephrinA5 binding in PCa will be required to address this possibility.

Ligand-dependent EphA7 signaling can both inhibit cell proliferation and survival signaling and induce apoptotic cell signaling. ${ }^{26,27}$ Akt, also known as PKB or Rac, is a pivotal protein kinase of the PI3K signaling pathway that regulates cell proliferation, survival and apoptosis via the downstream effectors such as the $\mathrm{Bcl}-2$ family. ${ }^{28}$ Downregulation of $\mathrm{Bcl}-2$ or upregulation of Bax may induce cell apoptosis and subsequently activate caspase- $3{ }^{22,27}$ Therefore, the present study examined the expression levels of Bcl-2 and Bax, and the activity of Akt and caspase-3, an apoptosis-associated protein. Overexpression of EphA7(WT) significantly decreased the expression of pAkt and $\mathrm{Bcl}-2$, and increased the expression of Bax and the activation of caspase-3, which can be further elevated by the stimulation of ephrinA5- $\mathrm{Fc}$ in $\mathrm{PC}-3$ cells. These results indicated that EphA7 induced PCa cell apoptosis predominantly via the PI3K/Akt signaling pathway. 
This study has some potential limitations regarding the mRNA expression of EphA7 and ephrinA5 in PCa tissues. First, laser microdissection could not be performed to isolate PCa cells, thus both epithelial cells and stromal cells could have contributed to the expression of EphA7 and ephrinA5. However, our IHC analysis suggests that the majority of EphA7 protein and ephrinA5 protein expression was from epithelial cells. Second, we cannot validate the role of endogenous ephrinA5 in EphA7 receptor phosphorylation via transfection of ephrinA5 expressing vector in PC-3 cells, but the similar study has been performed in both PC-3 cells treating with soluble ephrinA5-Fc and Du145 cells expressing very high levels of endogenous ephrinA5. Furthermore, the ligand-dependent antitumor effect of EphA7 receptor was confirmed in PC-3 cell line, because only PC-3 cell lines express very low levels of endogenous EphA7 and ephrinA5 in four prostate cell lines(RWPE-1, PC-3, LNCaP and DU145). Therefore, as a more general model for PCa, more PCa cell lines should be analyzed in the future.

In conclusion, the phosphorylated EphA7 can exert potential tumor-suppressive effects in regulating the development and progression of $\mathrm{PCa}$. In addition, the anticancer effect of EphA7 is dependent on the presence of the primary ligand ephrinA5 via targeting PI3K/Akt signaling pathways. Further understanding of the negative regulation of ligand-dependent EphA7 signaling will expand our knowledge of the molecular pathogenesis of $\mathrm{PCa}$. Our discovery provides novel insight into the mode of action of Eph receptors in cancer cells and represents a new facet in the complexities of Eph receptor function.

\begin{abstract}
Materials and Methods
Plasmids and site-directed mutagenesis. Human EphA7 (GenBank accession no. NM_004440.3) cDNAs were obtained from OriGene (Rockville, MD, USA). EphA7 mutants were generated using the site-directed gene mutagenesis kit (Stratagene, La Jolla, CA, USA). Tyr597, Tyr608, Tyr614 and Tyr791 were each replaced with phenylalanine in the kinase-dead (KD) mutant. We obtained the EphA7 cytoplasmic domain truncation mutant ( $\Delta$ Cyto, from $\mathrm{N}$-ter to Phe 576$)$ via PCR amplification. Then, EphA7 mutants were each subcloned into the pWPXLd vector (Invitrogen, Grand Island, NY, USA). Finally, lentivirus particles were generated in HEK293T cells harboring PSPAX2/pMD2.G packaging plasmid and various forms of the pWPXLd-EphA7 plasmid.
\end{abstract}

Cell culture, stimulation and protein overexpression. All cell lines were purchased from Chinese Academy of Sciences Cell Bank (Shanghai, China). RWPE-1 was cultured in defined keratinocyte-SFM supplemented with $5 \mathrm{ng} / \mathrm{ml}$ epidermal growth factor and $50 \mu \mathrm{g} / \mathrm{ml}$ bovine pituitary extract (Gibco, Carlsbad, CA, USA). HEK293T, LNCaP, PC-3 and DU145 cells were grown in RPMI-1640 containing $10 \% \mathrm{FBS}$ and $1 \%$ penicillin-streptomycin (Gibco). All cells were incubated at $37{ }^{\circ} \mathrm{C}$ in a humidified incubator containing $5 \% \mathrm{CO}_{2}$. PC-3 and DU145 cells were stably transfected using lentivirus particles, and selected with $400 \mathrm{mg} / \mathrm{l}$ G418 for neomycin resistance. For studies of soluble ephrinA5, cells were serum deprived for $24 \mathrm{~h}$ and then treated with $1 \mu \mathrm{g} / \mathrm{ml} \mathrm{Fc}$ or ephrinA5-Fc (R\&D Systems, Minneapolis, MN, USA) for the indicated times.

Clinical samples. Fifty BPH specimens, 64r PCa tissues and 20 paired noncancerous tissues were obtained from patients who underwent radical prostatectomy or prostate needle biopsies at the urology department of Huashan Hospital (Shanghai, China) and the Urology Department of the Affiliated Hospital of Xuzhou Medical University (Xuzhou, Jiangsu, China) between March 2013 and December 2016. All samples were verified by histological examination of sequential sections. Tumor stage was evaluated according to the 7th edition of the American Joint Committee on Cancer TNM (tumor node metastasis) classification system. Informed consent was obtained from all subjects, and the research protocol used in the present study was approved by the Ethics Committee of Huashan Hospital and the
Affiliated Hospital of Xuzhou Medical University. Patient clinical and histological characteristics are listed in Supplementary Table S1.

Quantitative real-time PCR. Total RNA was extracted and reverse transcribed with the Prim-Script RT Reagent Kit (TaKaRa, Dalian, China) according to the manufacturer's protocol. Quantitative real-time (qRT)-PCR was performed using the ABI Prism 7500 sequence detection system (Applied Biosystems, Foster City, CA, USA) and the TaqMan Gene Expression probe: Hs00177891_ml, Hs00157342_ml and Hs99999905_ml were used to detect EphA7, ephrinA5 and GAPDH, respectively (www.appliedbiosystems.com). The PCR cycle included one cycle at $95^{\circ} \mathrm{C}$ for $5 \mathrm{~min}$, followed by 40 cycles at $95{ }^{\circ} \mathrm{C}$ for $15 \mathrm{~s}$ and $60{ }^{\circ} \mathrm{C}$ for $34 \mathrm{~s}$.

IHC and imaging. The protein expression of EphA7, Ki-67, active-caspase-3 and ephrinA5 in tissue was determined using the following antibodies: rabbit anti-EphA7 polyclonal antibody (1:50, Abcam, Cambridge, UK), rabbit anti-Ki67monoclonal antibody (1:100, Cell Signaling Technology, CST, Danvers, MA, USA), rabbit anticleaved caspase-3 polyclonal antibody $(1: 100$, CST) and goat anti-ephrinA5 polyclonal antibody (1: 80 , R\&D Systems) via IHC assays as previously described. ${ }^{29}$

Western blotting and immunoprecipitation. Western blotting and immunoprecipitation were performed as previously described. ${ }^{30}$ Briefly, cells and tissues were lysed and then immunoprecipitated with an EphA7-specific antibody (CST). The protein was separated by $10 \%$ SDS-PAGE gels and then transferred to a polyvinylidene fluoride membrane. The membrane was incubated with the following antibodies: rabbit polyclonal antibody anti-EphA7 (1:1000, CST), antiEphA7(phospho Y791, 1:500, Abcam), anti-phospho-tyrosine (1:2000, CST), anti-t-Akt (1: 2000, CST), anti-p-Akt (1:1000, CST) anti-pro-caspase-3 $(1: 2000$, CST), anti-cleaved caspase-3 (1:1000, CST), anti-GAPDH (1:1000, CST), antiBcl-2 (1 : 1000, CST) and anti-Bax (1 : 1000, CST); goat polyclonal antibody antiephrinA5 (1: 1000, R\&D Systems); and mouse monoclonal antibody anti- $\beta$-actin $(1: 5000$, Proteintech, Rosemont, IL, USA). After the incubation of secondary antibody, the bands were detected using ECL western detection reagents in LAS-3000 system (Fuji Film, Tokyo, Japan).

Cell proliferation assay. PCa cells viability assay were carried out using a colorimetric WST-8 assay (Dojindo, Tokyo, Japan) as previously described. ${ }^{8}$

Scratch migration assay and invasion assay. Scratch migration assay and invasion assay were carried out as previously described. ${ }^{29}$

Subcutaneous xenograft tumor model. A subcutaneous xenograft tumor model was performed as previously described. ${ }^{29}$ Briefly, male BALB/c nude mice (4-6 weeks, 18-20 g) were purchased from the Slaccas Company (Shanghai, China) and fed under specific pathogen-free conditions. A total of $1 \times 10^{7} \mathrm{PC}-3$ cells harboring EphA7(WT), EphA7(KD), EphA7( $\Delta$ Cyto) or Control in $0.1 \mathrm{ml}$ saline suspension were mixed with $0.1 \mathrm{ml}$ of Matrigel (BD, Heidelberg, Germany) and subcutaneously injected between the scapulae of narcotized $\left(\mathrm{O}_{2} / \mathrm{CO}_{2}\right)$ mice (six mice per group). The mice were assessed daily and weighed once a week. The tumor sizes were measured using a dial caliper in a blinded manner and tumor volumes were calculated with the following formula: volume $=$ width $^{2} \times$ length $\times 0.52$. All animal protocols were approved by the Shanghai Medical Experimental Animal Care Commission. When primary tumors of control mice exceeded $2 \mathrm{~cm}^{3}$ or ulcerated the skin ( 49 days), mice were terminally narcotized and killed. Primary tumors were removed, weighed and processed for histologic examinations.

Statistics. The differences of gene expression levels between non-cancerous prostate tissue and PCa tumor tissues, as well as BPH tissue specimens and the associations of the expression of EphA7 and ephrinA5 with clinicopathological parameters in PCa tissues were evaluated by a chi-square test. Pearson correlation coefficients $(r)$ were calculated to evaluate the relationship between ephrinA5 expression and the ratio of $\mathrm{pEphA7/EphA7} \mathrm{in} \mathrm{PCa}$ tissues. Other data were analyzed by Student's $t$-test using SPSS 16.0 software (Chicago, USA). $P$-values $<0.05$ were considered statistically significant.

\section{Conflict of Interest}

The authors declare no conflict of interest. 
Acknowledgements. This work was supported by the National Natural Science Foundation of China (no. 81272386 and no. 81702061), the Specialized Research Fund for the Doctoral Program of Higher Education of China (no. 20120071110073), the Natural Science Foundation of Jiangsu Province (no. BK20160233), the Shanghai Leading Talent (2015) and the Jiangsu Provincial Medical Youth Talent (QNRC2016781).

\section{Author contributions}

SL performed the research, analyzed the data and wrote the initial manuscript; ZW, $P M, Y X$ and $Y C$ collected or assembled data and participated in writing the manuscript; HW, PH, ZK, LY and YZ analyzed the clinical data and contributed to clinical samples; $X Z, X X$, and $X M$ did the animal experiments and histologic assessment; MG designed the study and drafted the manuscript.

\section{Publisher's Note}

Springer Nature remains neutral with regard to jurisdictional claims in published maps and institutional affiliations.

1. Siegel RL, Miller KD, Jemal A. Cancer statistics, 2016. CA Cancer J Clin 2016; 66: 7-30.

2. Chen W, Zheng R, Baade PD, Zhang S, Zeng H, Bray $\mathrm{F}$ et al. Cancer statistics in China, 2015. CA Cancer J Clin 2016; 66: 115-132.

3. Gupta GP, Massagué J. Cancer metastasis: building a framework. Cell 2006; 127: 679-695.

4. Tay KJ, Mendez M, Moul JW, Polascik TJ. Active surveillance for prostate cancer: can we modernize contemporary protocols to improve patient selection and outcomes in the focal therapy era. Curr Opin Urol 2015; 25: 185-190.

5. Roach M. Current trends for the use of androgen deprivation therapy in conjunction with radiotherapy for patients with unfavorable intermediate-risk, high-risk, localized, and locally advanced prostate cancer. Cancer 2014; 120: 1620-1629.

6. Lisabeth EM, Falivelli G, Pasquale EB. Eph receptor signaling and ephrins. Cold Spring Harb Perspect Biol 2013; 5 pii: a009159.

7. Pasquale EB. Eph receptor signalling casts a wide net on cell behaviour. Nat Rev Mol Cell Biol 2005; 6: 462-475.

8. Guan M, Xu C, Zhang F, Ye C. Aberrant methylation of EphA7 in human prostate cancer and its relation to clinicopathologic features. Int J Cancer 2009; 124: 88-94.

9. Wang J, Kataoka H, Suzuki M, Sato N, Nakamura R, Tao H et al. Downregulation of EphA7 by hypermethylation in colorectal cancer. Oncogene 2005; 24: 5637-5647.

10. Eberle FC, Rodriguez-Canales J, Wei L, Hanson JC, Killian JK, Sun HW et al. Methylation profiling of mediastinal gray zone lymphoma reveals a distinctive signature with elements shared by classical Hodgkin's lymphoma and primary mediastinal large B-cell lymphoma. Haematologica 2011; 96: 558-566.

11. López-Nieva $P$, Vaquero $C$, Fernández-Navarro $P$, González-Sánchez L, Villa-Morales $M$ Santos $\mathrm{J}$ et al. EPHA7, a new target gene for $6 \mathrm{q}$ deletion in T-cell lymphoblastic lymphomas. Carcinogenesis 2012; 33: 452-458.

12. Li YF, Hsiao YH, Lai YH, Chen YC, Chen YJ, Chou JL et al. DNA methylation profiles and biomarkers of oral squamous cell carcinoma. Epigenetics 2015; 10: 229-236.

13. Oricchio $E$, Wendel $H G$. Functional genomics lead to new therapies in follicular lymphoma. Ann N Y Acad Sci 2013; 1293: 18-24.

14. Oricchio $E$, Nanjangud $G$, Wolfe $A L$, Schatz JH, Mavrakis KJ, Jiang $M$ et al. The Eph-receptor A7 is a soluble tumor suppressor for follicular lymphoma. Cell 2011; 147 554-564.

15. Noberini R, de la Torre ER, Pasquale EB. Profiling Eph receptor expression in cells and tissues: a targeted mass spectrometry approach. Cell Adh Migr 2012; 6: 102-112.
16. Taneja R, Thisse B, Rilli FM, Thisse $C$, Bouillet $P$, Dollé $P$ et al. The expression pattern of the mouse receptor tyrosine kinase gene MDK1 is conserved through evolution and requires Hoxa-2 for rhombomere-specific expression in mouse embryos. Dev Biol 1996; 177 : 397-412.

17. Hafner C, Schmitz G, Meyer S, Bataille F, Hau P, Langmann T et al. Differential gene expression of Eph receptors and ephrins in benign human tissues and cancers. Clin Chem 2004; 50: 490-499.

18. Wang J, Li G, Ma H, Bao Y, Wang X, Zhou H et al. Differential expression of EphA7 receptor tyrosine kinase in gastric carcinoma. Hum Pathol 2007; 38: 1649-1656.

19. Wang LF, Fokas E, Juricko J, You A, Rose F, Pagenstecher A et al. Increased expression of EphA7 correlates with adverse outcome in primary and recurrent glioblastoma multiforme patients. BMC Cancer 2008; 8: 79.

20. Giaginis C, Tsourouflis G, Zizi-Serbetzoglou A, Kouraklis G, Chatzopoulou E, Dimakopoulou $\mathrm{K}$ et al. Clinical significance of ephrin (eph)-A1, -A2, -a4, -a5 and -a7 receptors in pancreatic ductal adenocarcinoma. Pathol Oncol Res 2010; 16: 267-276.

21. Giaginis C, Tsoukalas N, Bournakis E, Alexandrou P, Kavantzas N, Patsouris E et al. Ephrin (Eph) receptor A1, A4, A5 and A7 expression in human non-small cell lung carcinoma: associations with clinicopathological parameters, tumor proliferative capacity and patients survival. BMC Clin Pathol 2014; 14: 8

22. Li R, Sun Y, Jiang A, Wu Y, Li C, Jin M et al. Knockdown of ephrin receptor A7 suppresses the proliferation and metastasis of A549 human lung cancer cells. Mol Med Rep 2016; 13: 3190-3196.

23. Xiang C, Lv Y, Wei Y, Wei J, Miao S, Mao X et al. Effect of EphA7 silencing on proliferation, invasion and apoptosis in human laryngeal cancer cell lines Hep-2 and AMC-HN-8. Cell Physiol Biochem 2015; 36: 435-445.

24. Oudes AJ, Roach JC, Walashek LS, Eichner LJ, True LD, Vessella RL et al. Application of Affymetrix array and massively parallel signature sequencing for identification of genes involved in prostate cancer progression. BMC Cancer 2005; 5: 86.

25. Lee H, Park E, Kim Y, Park S. EphrinA5-EphA7 complex induces apoptotic cell death via TNFR1. Mol Cells 2013; 35: 450-455.

26. Lee H, Park S, Kang YS, Park S. EphA receptors form a complex with caspase-8 to induce apoptotic cell death. Mol Cells 2015; 38: 349-355.

27. Bhatia S, Hirsch K, Baig NA, Rodriguez O, Timofeeva O, Kavanagh $\mathrm{K}$ et al. Effects of altered ephrin-A5 and EphA4/EphA7 expression on tumor growth in a medulloblastoma mouse model. J Hematol Oncol 2015; 8: 105

28. Fulda S. Modulation of mitochondrial apoptosis by PI3K inhibitors. Mitochondrion 2013; 13 195-198.

29. Li S, Ma Y, Xie C, Wu Z, Kang Z, Fang Z et al. EphA6 promotes angiogenesis and prostate cancer metastasis and is associated with human prostate cancer progression. Oncotarget 2015; 6: 22587-22597.

30. Taddei ML, Parri M, Angelucci A, Onnis B, Bianchini F, Giannoni E et al. Kinase-dependent and -independent roles of EphA2 in the regulation of prostate cancer invasion and metastasis. Am J Pathol 2009; 174: 1492-1503.

(c) (i) Cell Death and Disease is an open-access journal published by Nature Publishing Group. This work is licensed under a Creative Commons Attribution 4.0 International License. The images or other third party material in this article are included in the article's Creative Commons license, unless indicated otherwise in the credit line; if the material is not included under the Creative Commons license, users will need to obtain permission from the license holder to reproduce the material. To view a copy of this license, visit http://creativecommons.org/licenses/by/4.0/

C) The Author(s) 2017

\section{Supplementary Information accompanies this paper on Cell Death and Disease website (http://www.nature.com/cddis)}

